\title{
Ultrastructural study on the development of Goussia aculeati, a coccidium parasitizing the three-spined stickleback Gasterosteus aculeatus
}

\author{
Miroslaw Jastrzębski \\ Department of Parasitology and Parasitic Diseases, Veterinary Faculty, Agricultural University, 03-849 Warsaw, \\ ul. Grochowska 272, Poland
}

\begin{abstract}
Goussia aculeati developed in the parasitophorous vacuole situated intraplasmatically between nucleus and apical end of the intestinal epithelium cell of the three-spined stickleback Gasterosteus aculeatus (L.). A single membrane of the parasitophorous vacuole formed numerous intravacuolar blebs, which detached to be absorbed by the parasite micropores or invaginations on its surface. All developmental stages of the parasite, except merozoites, were surrounded by a single membrane. Meronts of one of the last generations were formed through ectomerogony. Few microgametes formed on the surface or in the deep fissures of the microgamont. In macrogamonts, 2 types of electron-dense membrane-bound bodies were seen: small ones, up to $600 \mathrm{~nm}$ in diameter, round and homogenous; and large ones of irregular electron-density, up to $1.9 \mu \mathrm{m}$ in diameter. Role and origin of these bodies in $G$. aculeati remain unknown.
\end{abstract}

\section{INTRODUCTION}

Goussia aculeati is one of the 2 species of coccidia parasitizing the intestine of three-spined stickleback Gasterosteus aculeatus (L.). Light microscope investigations have shown that $G$. aculeati develops in the cytoplasm of intestinal epithelium cells (Jastrzębski 1984, Jastrzębski et al. 1988), whereas the other intestinal species of three-spined stickleback coccidia Goussia zarnowskii - localizes superiorily to the host cell cytoplasm, under its surrounding membrane, as light and electron microscopy results have indicated (Jastrzębski \& Komorowski in press).

In recent years, developmental stages of fish coccidia have frequently been subject to ultrastructural examinations; however the investigations concerned mainly either parenteral coccidia (Hawkins et al. 1983a, b, Morrison \& Hawkins 1984, Landsberg \& Paperna 1985, Paperna et al. 1986) or epiplasmatically localized intestinal coccidia (Daudi et al. 1986, Landsberg \& Paperna 1986, Molnar \& Baska 1986, Jastrzębski \& Komorowski in press). Only 2 species of intraplasmatically developing fish coccidia of intestinal epithelium cells have been described in detail, i.e. Goussia irroquoina parasitizing intestines of Notropis cornutus and Pimephales promelas (Molnar \& Fernando 1974, Paterson \& Desser 1981a, b, c, 1984) and G. laureleus parasitizing the intestine of Perca flavescens (Molnar \& Fernando 1974, Desser \& Li 1984). It should be stressed that this intraplasmatic model of development is typical for most species of fish coccidia. The ultrastructural description of the development of $G$. aculeati is therefore aimed at contributing to our knowledge of this largest group of fish coccidia.

\section{MATERIALS AND METHODS}

Three-spined sticklebacks Gasterosteus aculeatus (L.) caught in spring and autumn in a carp pond farm of the Inland Fishery Institute, Źabieniec (Poland), were dissected in search of Goussia aculeati aocysts. For this purpose fecal contents of the hindgut ( 3 to $5 \mathrm{~mm}$ in length) were pressed out. When numerous unsporulated or sporulated oocysts of $G$. aculeati were found in the pressed-out material, the scrapings of foregut and midgut mucous membrane were collected for ultrastructural examination. The material thus collected was fixed in $2 \%$ paraformaldehyde solution with $2.5 \%$ glutaraldehyde in cacodylate buffer $\mathrm{pH} 7.4$ (for $24 \mathrm{~h}$ ) and 
postfixed with $1 \%$ osmium tetroxide in the same buffer. Subsequently the samples were dehydrated in an ascending series of alcohols and treated with propylene oxide. Tissues were embedded in Epon 812. Ultrathin sections were cut with a glass knife, mounted on uncoated, copper grids, stained with uranyl acetate and lead citrate, and examined under a JEM 100 C electron microscope. Unsporulated oocysts collected in pressedout fish feces were incubated in tap water $\left(20^{\circ} \mathrm{C}\right)$ for $48 \mathrm{~h}$ in order to confirm the parasite's species classification.

\section{RESULTS}

In sticklebacks naturally infected with Goussia aculeati, electron microscopic examination revealed the following developmental stages of the parasite: trophozoites, meronts, micro- and macrogamonts. All these parasite forms developed in the parasitophorous vacuole (PV) in the intestinal epithelium cells, localized between nucleus and host-cell apical pole. The PV was surrounded by a single-unit membrane. On the host-cell cytoplasm side were dilated cisternae of rough endoplasmic reticulum (ER) adjacent at numerous sites, as well as many adhering vacuoles, surrounded by single- unit membrane (Figs. 1 and 2). The PV membrane often formed intravacuolar blebs containing a fine vacuole, or even a fragment of host-cell cytoplasm with ribosomes, sometimes with a few fine vacuoles. These protrusions would probably become detached from the PV membrane and pass into the PV space to form double. membraned fine vesicles, or bigger vesicles containing ribosomes and a few fine vacuoles (Fig. 2). Such formations were clearly visible also in the peripheral area of the parasite cytoplasm and in its surface invaginations. In the PV space their reticulated contents as well as free ribosomes could be observed (Figs. 1 and 2). Intravacuolar microtubules were absent.

\section{Trophozoites}

Usually a single intestinal cell was invaded by a single parasite, less often by 2 parasites. Trophozoites, being very early forms of meronts or gamonts, were surrounded by single continuous membrane (plasmalemma) with several remnants of the double-membraned inner pellicular complex (IPC) visible beneath it (Fig. 1). Pellicular microtubules were absent. In some trophozoites, single micropores and surface invaginations into cytoplasm

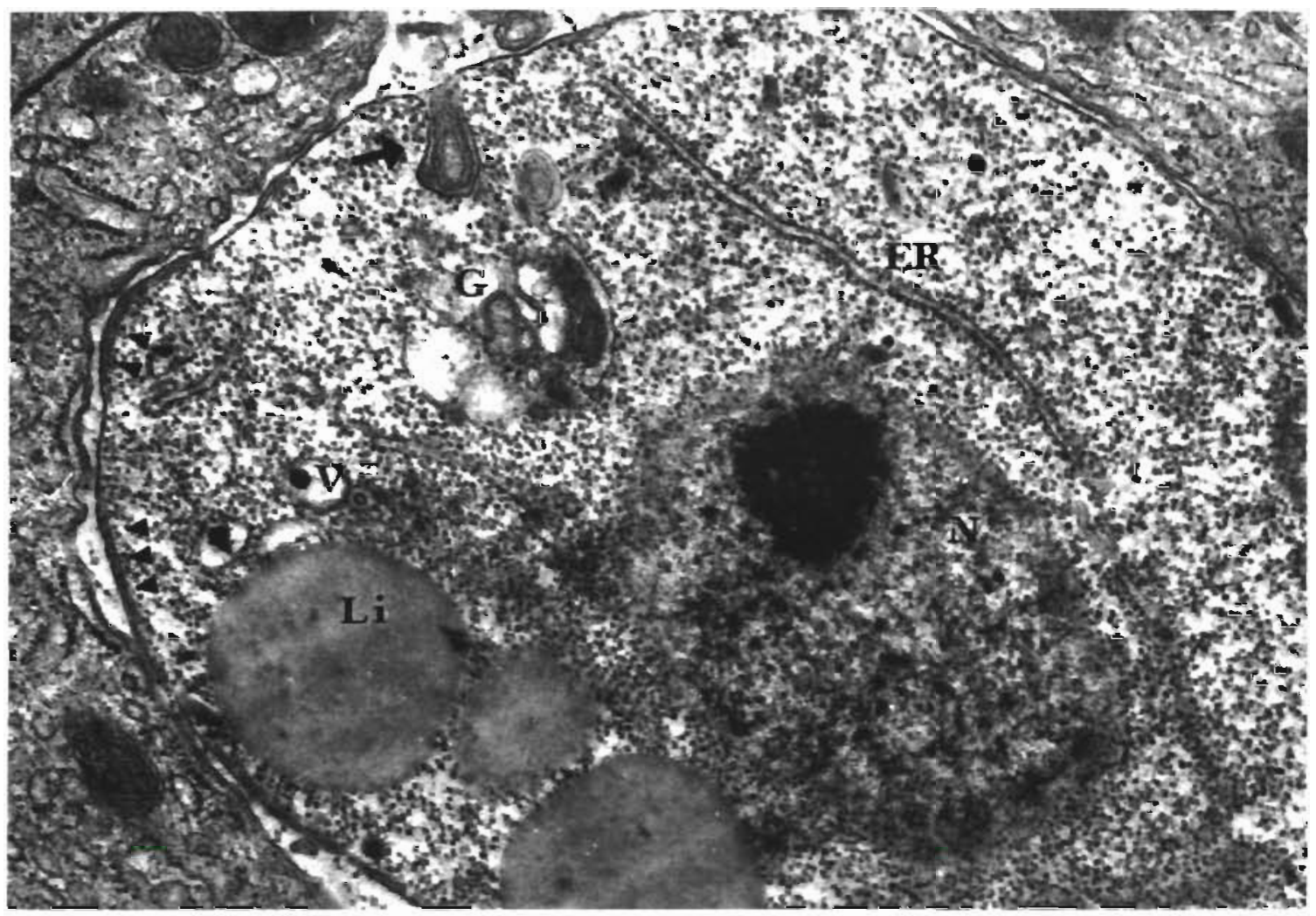

Fig. 1. Goussia aculeati. Trophozolte. Note remnants of double-membraned pellicular complex (arrowheads) and surface invagination with ingested double-membraned vesicle (arrow). ER: rough endoplasmic reticulum; G: Golgi complex; Li: lipid body: $N$ : nucleus with nucleolus; $V$. vacuole containing small osmiophilic granule. $(\times 33000)$ 


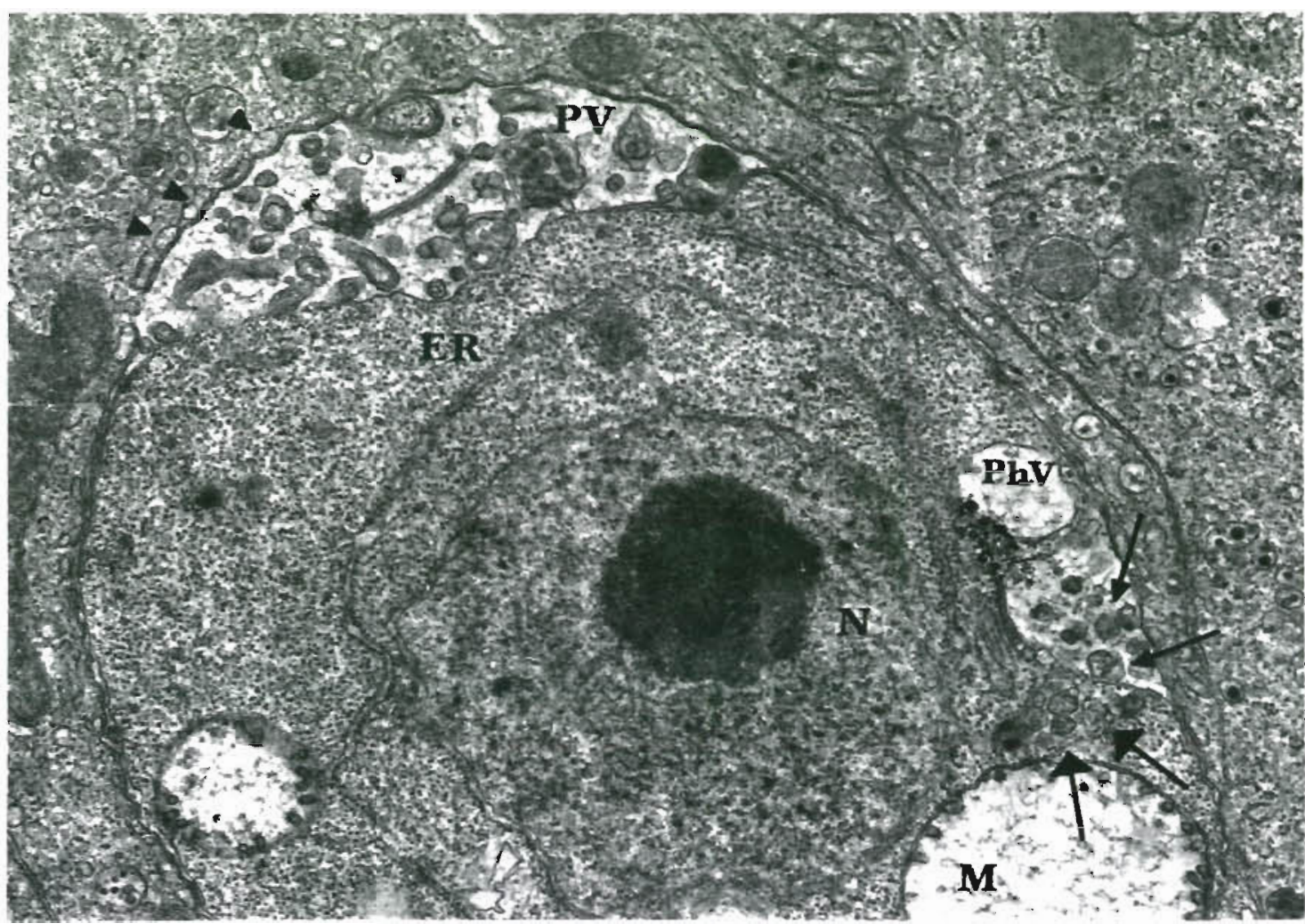

Fig. 2. Goussia aculeati. Trophozoite. Numerous blebs and double-membraned vesicles seen in parasitophorous vacuole (small arrows) as well as in the parasite cytoplasm (large arrows). Note fine vesıcles adhered to PV membrane in the host-cell cytoplasm (arrow-heads). ER: endoplasmic reticulum; $\mathrm{M}$ : mitochondrion; $\mathrm{N}$ : nucleus with nucleolus; PhV: phagocytic vacuole. ( $\times 21000$ )

were visible (Fig. 1). In the parasite cytoplasm organelles could be seen, such as a single nucleus with a distinct nucleolus, the Golgi complex, small vacuoles frequently containing fine dense granules, single large mitochondria with tubular cristae, and free ribosomes. In addition, single micronemes and round large size lipid bodies were found. The rough ER was usually observed as having formed into long canaliculi (Figs. 1 and 2). Characteristically, in PV surrounding trophozoites numerous blebs were visible as well as vesicles containing fine vacuoles and fragments of host-cell cytoplasm, whereas in the PV surrounding more advanced meronts and gamonts these were much less numerous.

\section{Meronts}

Early meronts were, analogically to trophozoites, surrounded by a continuous plasmalemma. Within the cytoplasm a few nuclei with nucleoli, peripheral mitochondria, single scattered micronemes, lipid bodies and single small vacuoles were visible (Fig. 3). During meront development, rough ER quantity significantly increased, thus most probably providing membranous material for the subsequently produced merozoites. Under the meront plasmalemma at this stage of development, elements of the future apical complexes of merozoites first appeared; this clearly indicated that merozoites formed through ectomerogony (Fig. 4). Between the newly-formed apical complex and the merozoite nucleus, Golgi complex vesicles and rhoptry anlagen were visible. A crosssection through a mature meront showed a few (up to 6) merozoites (Fig. 5). The merozoites were surrounded by a 3-membraned pellicle. A nucleus with a nucleolus, the Golgi complex, rough ER, mitochondrion, rhoptries, micronemes and a conoid with 2 preconoidal rings were visible in the merozoite cytoplasm (Fig. 5). In some of the meronts the less osmiophilic meront cytoplasmal residuum was visible containing ribosomes, vacuoles and dilated ER cisternae.

\section{Microgamonts}

In the material examined, only considerably advanced developmental forms of microgamonts were found, surrounded by a single continuous limiting membrane. Microgametes under formation were visible both on the gamonts' peripheries, and in its deep 


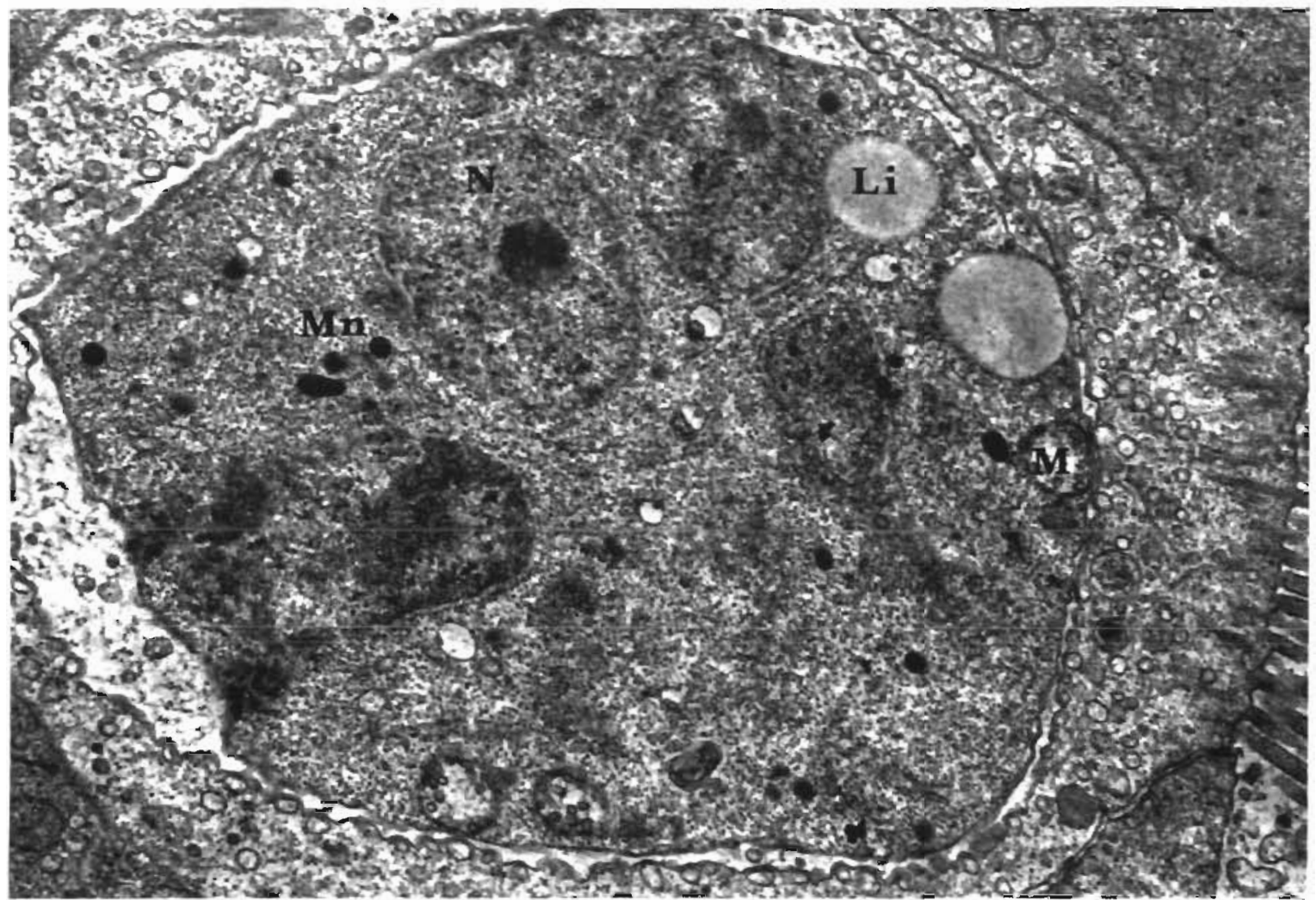

Fig. 3. Goussia aculeati. Early multinucleate meront. Li: lipid body; M: mitochondrion; Mn: micronemes; N: nucleus. $(\times 20000)$

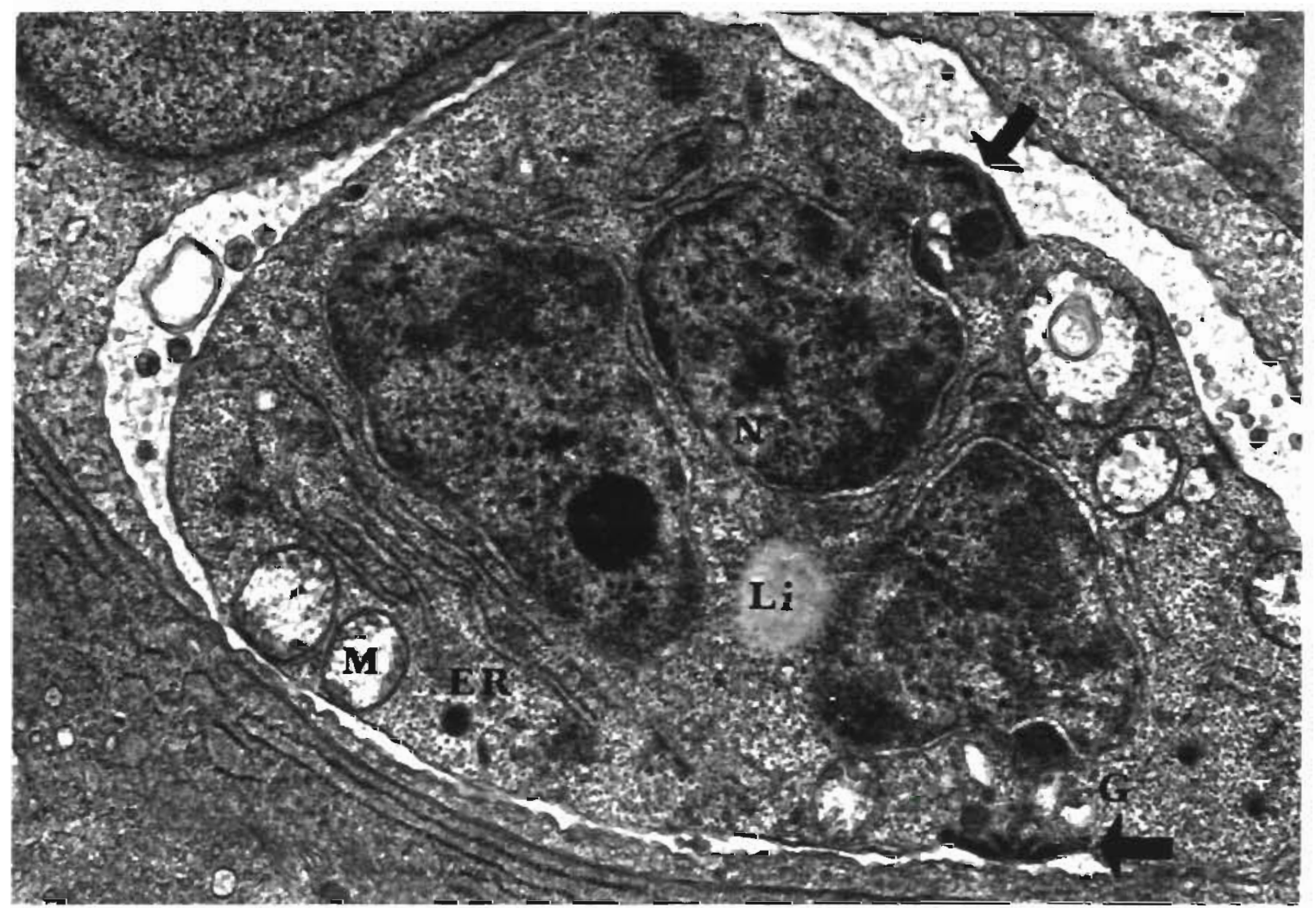

Fig. 4. Goussia aculeati. More advanced multinucleate meront with distinct apical complex anlagen under the parasite plasmalemma (arrows). ER: rough endoplasmic reticulum; G: Golgi complex; Li: lipid body; M: mitochondrion; N: nucleus. ( $\times 20$ 000) 


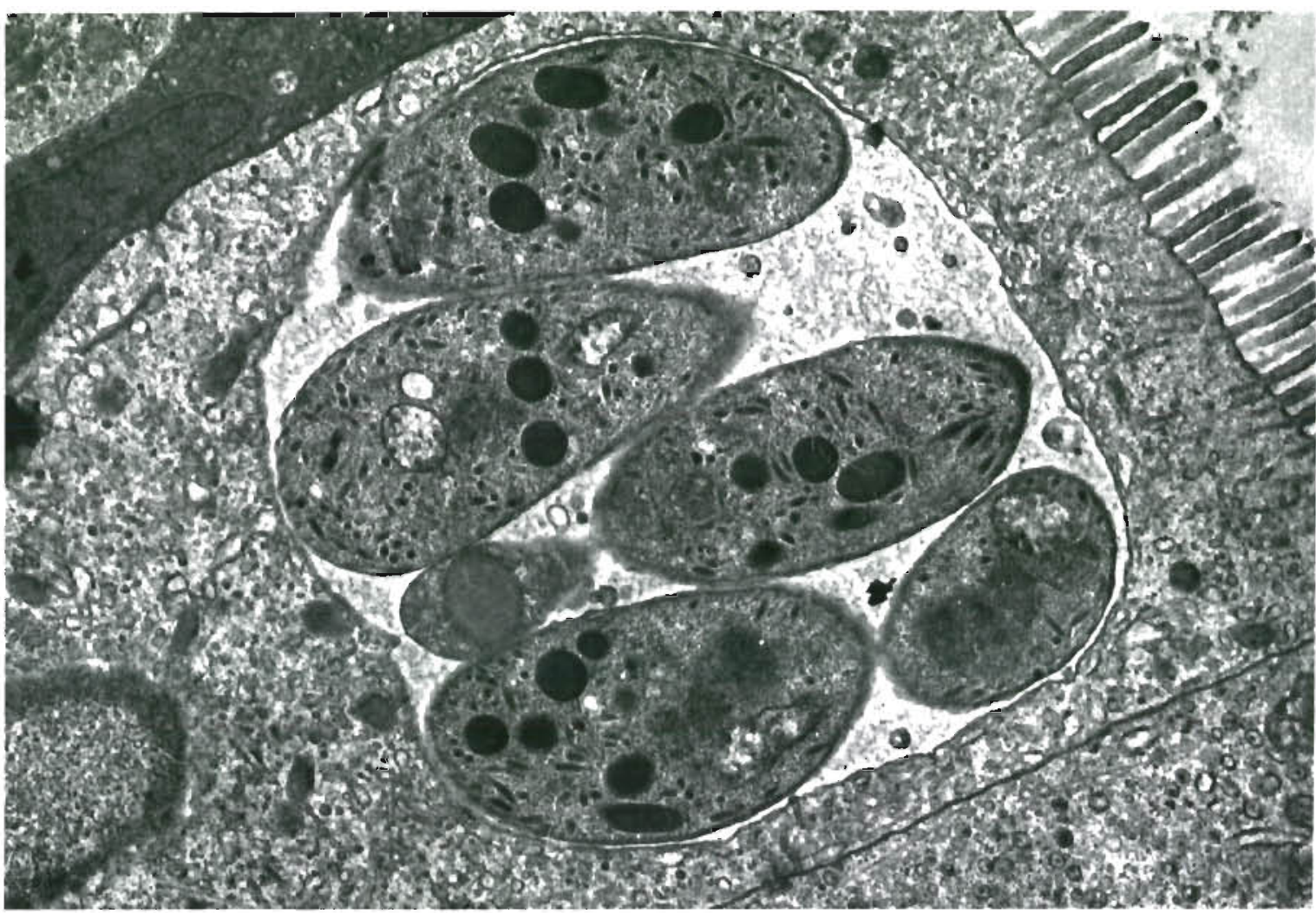

Fig. 5. Goussia aculeati. Mature meront with distinct merozoites. $(\times 17000)$

surface invaginations (fissures) flagellae appeared, followed by a protruding microgametic nucleus with dense heterochromatin. The bright part of the nucleus of the newly-forming microgamete remained in the microgamont cytoplasm as a residual nucleus. In the gamont cytoplasm, numerous mitochondria were also present, usually situated beside the nuclei of the microgametes under formation, and mitochondria with concentric multimembranous material. Moreover, small quantities of rough ER with dilated canaliculi were found, as well as Golgi complexes, lipid bodies, scarce micronemes and scattered ribosomes (Fig. 6).

In mature microgamonts, single microgametes with flagellae could be observed budding off the microgamont surface into the PV space. The plasmatic residuum of the microgamont grew brighter in the course of its development and contained vast areas of loose reticular structures, without ribosomes or any other organelle. In the darker portion of cytoplasm, containing ribosomes, double-membrane bound bright residual nuclei were visible, as well as dilated ER canaliculi, single vacuoles, lipid bodies and single micronemes scattered in the gamont peripheral area (Fig. 7).

The microgamete consisted of a nucleus with dense osmiophilic chromatin, surrounded by a double-membraned nuclear envelope, and an oblong mitochon- drion as well as 4 microtubules passing along the nucleus and mitochondrion (Fig. 7, inset). The anterior end of the microgamete was armed with perforatorium and a rod-like structure projecting from it (Fig. 7). The entire microgamete was surrounded by a single continuous membrane derived from the microgamont plasmalemma. The number of microgametes produced was rather small; in maturing microgamonts, in a single cross-section, up to 19 gametes were found.

\section{Macrogamonts}

In the macrogamont material examined, 2 forms could be distinguished being more or less advanced in their development. The earlier stages were surrounded by a single continuous membrane under which, only at some spots, remnants of double-membraned IPC could be found. In the cytoplasm of such a young macrogamont, a large nucleus with a distinct nucleolus was noticeable, enveloped in a double membrane, as well as concentrations of rough ER canaliculi, peripheral small mitochondria and fine vacuoles. In the cytoplasm between the rough ER canaliculi, membrane-bound polysaccharide granules could be observed under formation, a few in the beginning stages. In addition, 


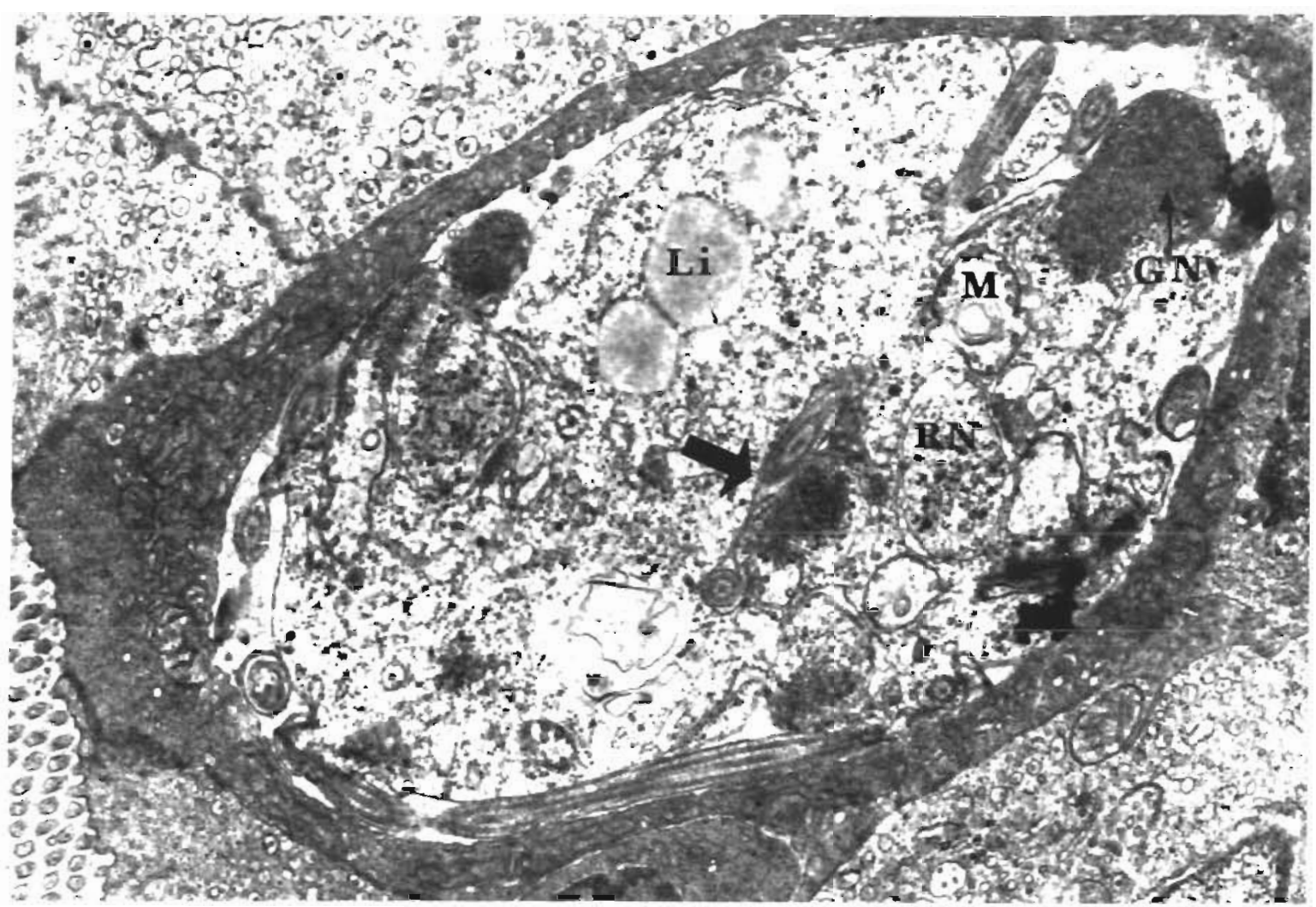

Fıg. 6 Coussia aculeati Microgamont with mucrogametes budding into the PV and into deep invagination (wide arrow). GN: gamete nucleus; Li. lipıd body, $M$ mitochondnon, RN residual nucleus. ( $\times 16000)$

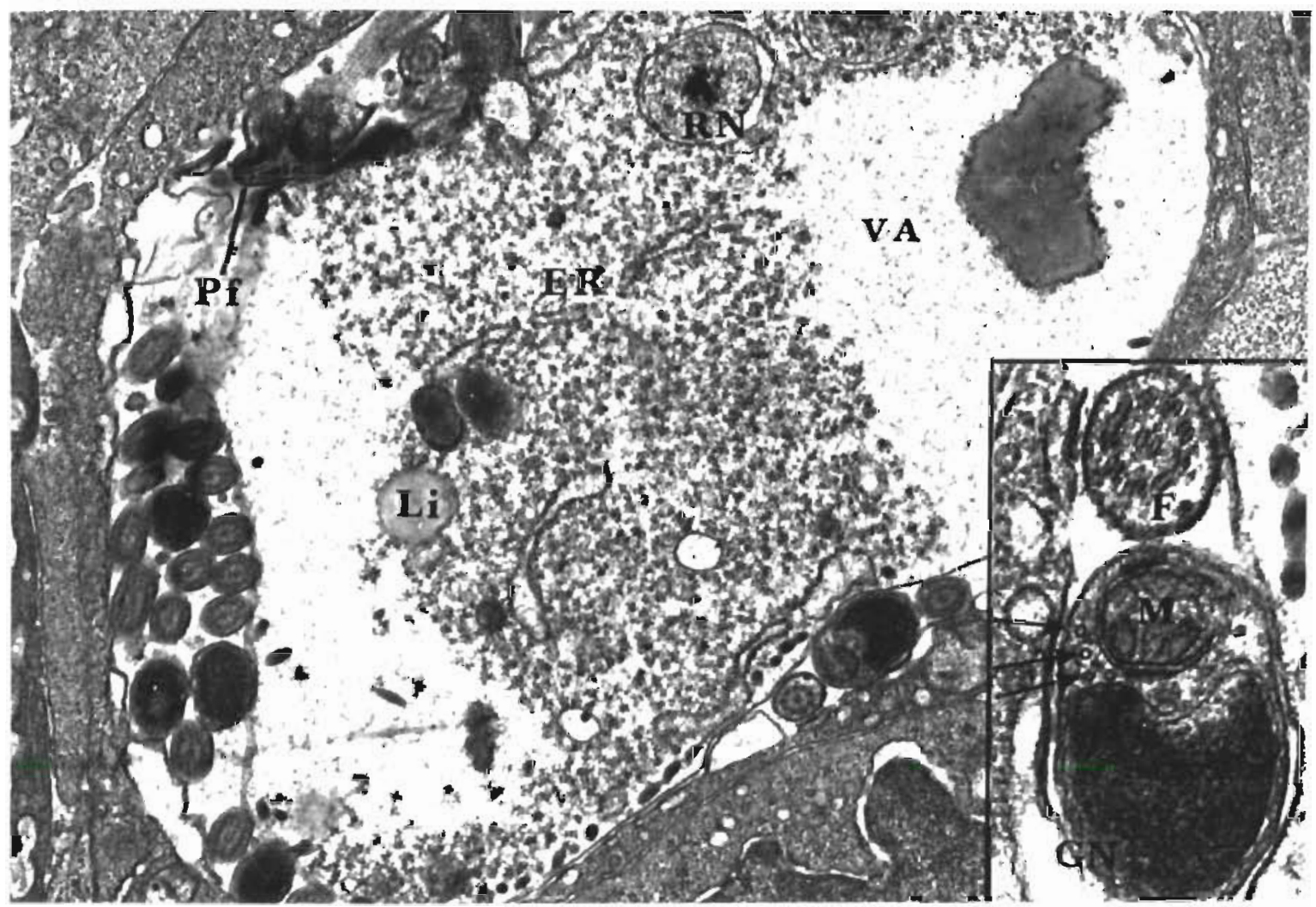

Flg 7 Goussta aculeati. Mature microgamont. Two vast areas of gamont cytoplasm without any organelles can be seen on 2 poles of microgamont ER: endoplasmic reticulum; Li: lipid body; Pf: microgamete perforatorium; RN: residual nucleus; VA: vast area; ( $\times 180001$ Inset: cross section through microgamete. Note 4 microtubules (arrows). F; flagellum; GN; gamete nucleus; $M$ : 


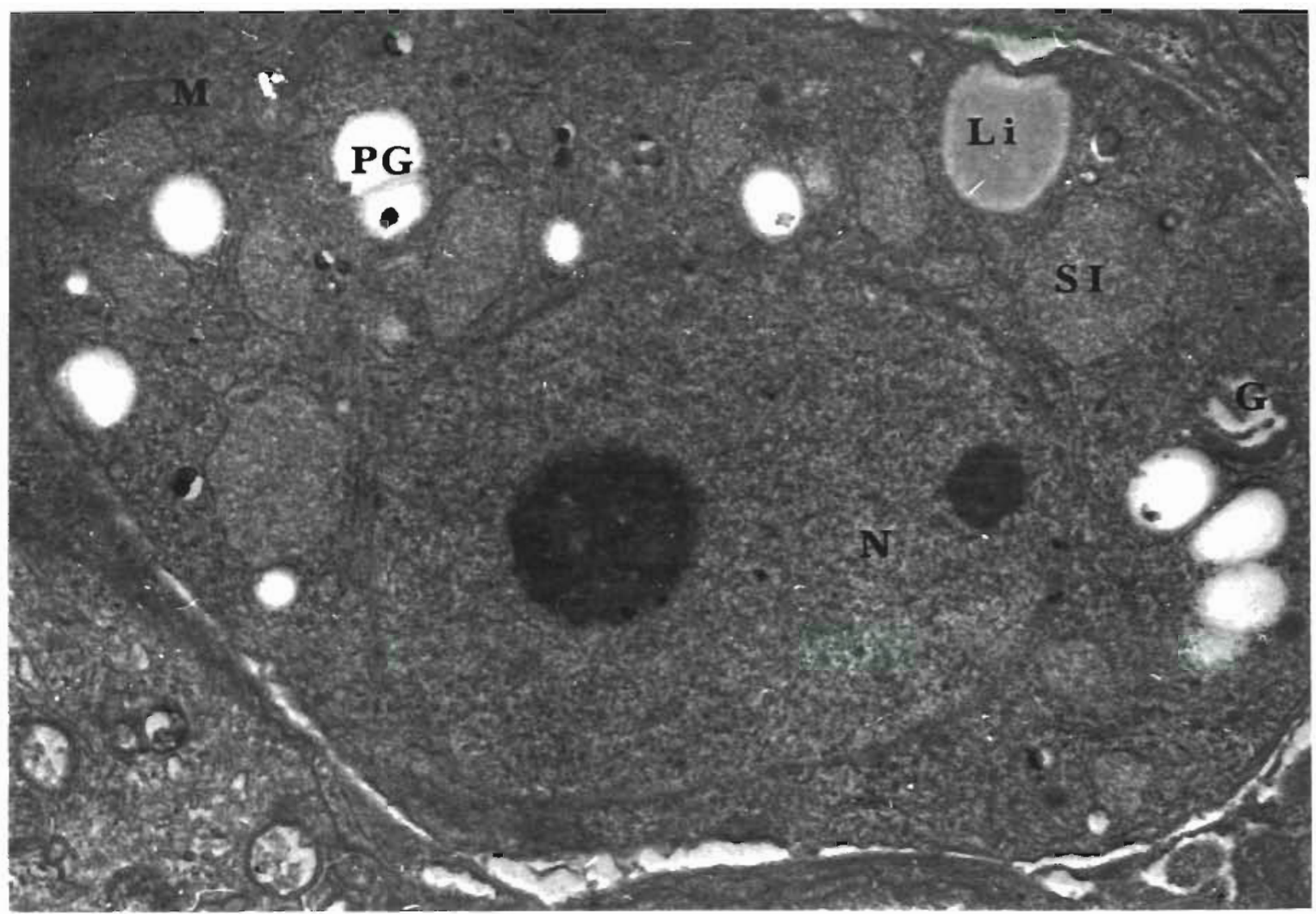

Fig. 8. Goussia aculeati. Early macrogamont. G: Golgi complex; Li: lipid body; M: mitochondrion; N: nucleus; PG: polysaccharide granule; SI: spongiform inclusion. $(\times 16000)$

numerous membrane-bound inclusions of moderate electron density and a slightly spongiform structure ( 800 to $1300 \times 420$ to $980 \mathrm{~nm}$ ) were visible. The PV space was narrow, but still distinct (Fig. 8).

In advanced forms of macrogamont development, polysaccharide granules appeared in significantly increased quantities and of considerably larger size when compared to those in the earliest forms. On the other hand, the numbers of ER canaliculi and of mitochondria decreased. Spongiform inclusions were not visible at this stage of development. Apart from the above-mentioned changes, in the cytoplasm of advanced macrogamonts, membrane-bound lipid bodies and also membrane-bound electron-dense bodies of various sizes appeared: (1) large bodies (up to $1.9 \mu \mathrm{m}$ ) of irregular density and irregularly round shapes $(\mathrm{Mx})$; (2) small bodies (up to $600 \mathrm{~nm}$ in diameter), homogeneous, of high electron-density and of regularly round shapes (Mv). In some microphotographs, small round granules of similar or less osmiophilic electron-density were observed in the course of separating from the larger bodies $(\mathrm{Mx})$ or connecting with them (Fig. 9). Such macrogamonts were surrounded by a single continuous membrane without any IPC remnants. The PV space was, at this stage of development, very narrow and often hardly discernible (Fig. 9).

\section{DISCUSSION}

Our ultrastructural investigations on the development of Goussia aculeati in three-spined sticklebacks indicate considerable similarity of developmental stages to the development of other intraplasmatic fish coccidia, in particular Goussia irroquoina parasitizing intestinal epithelium cells of Notropis cornutus and Pimephales promelas (Paterson \& Desser 1981a, b, c, 1984). An interesting characteristic of $G$. irroquoina development is its differentiated merogony: the first generations of merozoites are formed from ectomerogony, whereas the last generation preceding gamogony is formed through endomerogony, In $G$. aculeati the number of meront generations cannot be precisely determined, since only naturally infected sticklebacks have been examined. However, on the premises of light-microscopy results, at least 3 generations of merogony are supposed to exist (Jastrzȩbski et al. 1988). The present paper indicates that in one of the merogonies (probably in the last one) merozoites are formed through ectomerogony. In a similar study, concerning the development of Epieimeria anguillae in European eels, Molnar \& Baska (1986) described endomerogony, similar to that in $G$. irroquoina, in one of the last generations of meronts. 


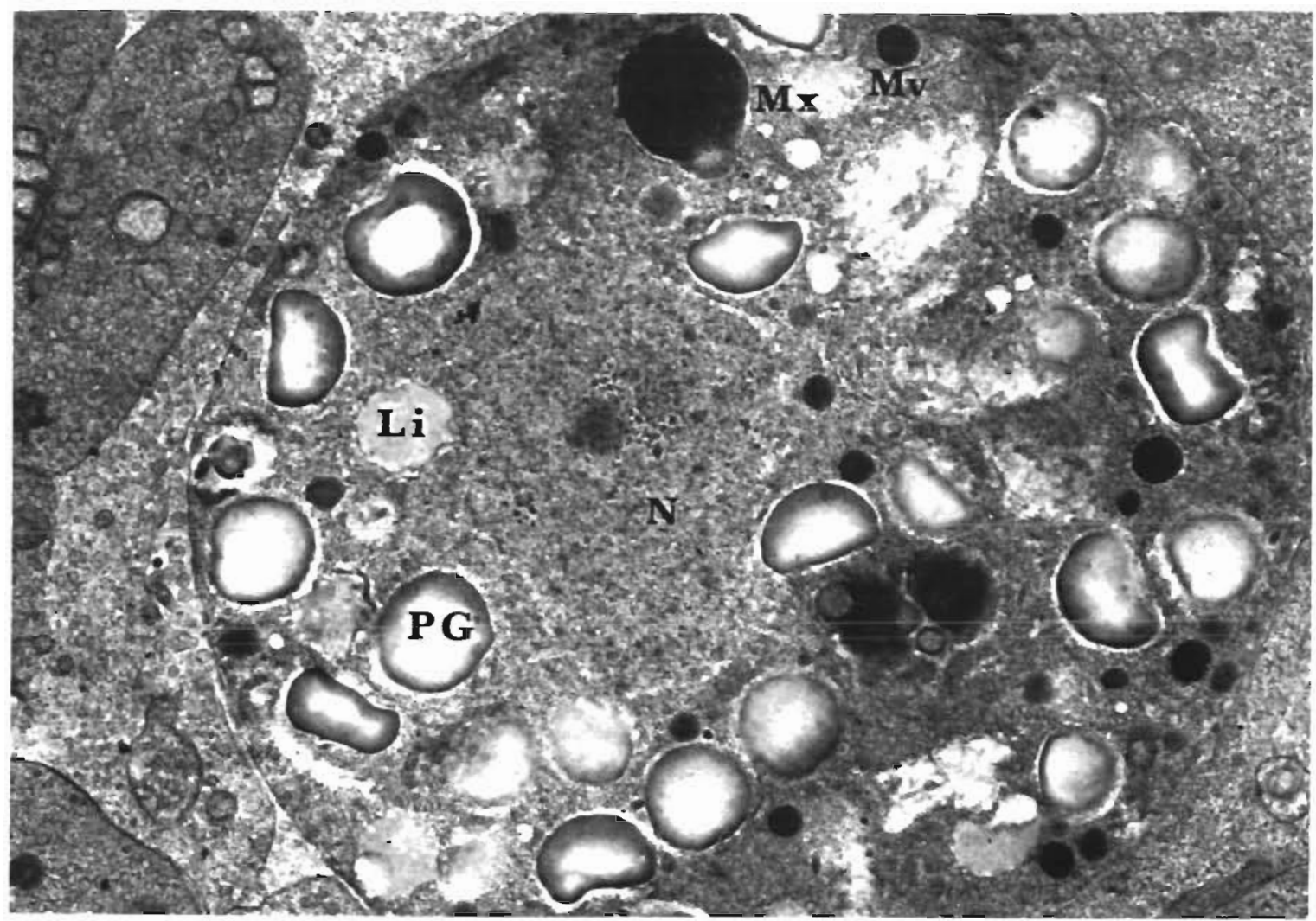

Fig. 9. Goussia aculeati. Maturing macrogamont. Li: lipid body; Mv: small round electron-dense bodies; Mx: dense large bodies; N: nucleus with nucleolus; PG: polysaccharide granule. $(\times 12500)$

Microgametes of Goussia aculeati form in small numbers both on the surface and in deep fissures of gamont cytoplasm - very similar to the microgametogenesis in G. irroquoina (Paterson \& Desser 1981c) and, to a lesser degree, that in E. anguillae (Molnar \& Baska 1986). However, deep invaginations were not noted in microgamonts of Calyptospora funduli (Hawkins et al. 1983b), G. laureleus (Desser \& Li 1984) and G. zarnowskii (Jastrzębski \& Komorowski in press).

Paterson \& Desser $(1981 b, 1984)$ described in macrogametes of Goussia irroquoina 2 types of electrondense membrane-bound bodies: smaller, round membrane-bound vesicles ( $\mathrm{Mv}$ ) and larger ones, of electrondense material $(\mathrm{Mx})$, which were formed, according to the authors, through cumulating smaller inclusions (Mv). Two almost identical types of electron-dense bodies were found in $G$. aculeati macrogametes, and their 'Mv' and ' $M x^{\prime}$ ' symbols have been accepted after Paterson \& Desser. The phenomenon of smaller bodies $(\mathrm{Mv})$ merging into larger ones $(\mathrm{Mx})$, analogical to that observed in G. irroquoina, was also noted, although a contrary interpretation cannot be excluded, i.e. smaller formations may be detached from larger ones. Moreover, it is also possible that the precursors of the $\mathrm{Mx}$ inclusions are, in $G$. aculeati, moderate electron- dense bodies of slightiy spongiform structure (SI) found only in very young, but yet recognizable, macrogamonts. The role of $\mathrm{Mv}, \mathrm{Mx}$ and $\mathrm{SI}$ inclusions in $G$. aculeati is still unknown, since the further stages of macrogamete and zygote development require investigations. However, Paterson \& Desser (1984) assumed that $\mathrm{Mx}$ inclusions were the precursors of refractile bodies in sporoblasts and sporozoites of $G$. irroquoina.

Similarly, the general problem concerning fish coccidia is their mode of feeding in the host cell. It is rather certain that the epiplasmatic coccidia, parasitizing like the members of Epieimeria and Cryptosporidium, have a different pattern of nutrient uptake from the intraplasmatic coccidia, such as those of the genera Eimeria, Goussia and Calyptospora. The first group of coccidia probably absorbs nutrients only through the adhesive zone formed by the parasitophorous vacuole penetrating with its processes into host-cell cytoplasm (Daudi et al. 1986, Molnar \& Baska 1986, Paperna et al. 1986, Jastrzȩbski \& Komorowski in press), or through feeder organelle protrusions typical for members of the genus Cryptosporidium (Landsberg \& Paperna 1986). Unlike the above, coccidia parasitizing in fishes in a typical intraplasmatic PV feed through producing intravacuolar blebs, which contain elements of host-cell cyto- 
plasm. According to Hawkins et al. (1983a, b) and Morrison \& Hawkins (1984), nutrient materials are accumulated in the host-cell ER cisternae, neighbouring the PV membrane, to be subsequently formed into blebs, which are detached and pass into the PV space, joined with the parasite surface and absorbed into its cytoplasm. Such a phenomenon was also found in $G$. aculeati, which thus contributes to the list of fish coccidia without intravacuolar microtubules and folds of PV membrane. The PV membrane's 'feeding activity' is markedly higher in $G$. aculeati in fast-growing trophozoites than in developing or mature meronts or gamonts. In mature macrogamonts the number of mitochondria also decreases in comparison to their earlier stages. Pitillo \& Ball (1979) account for a similar phenomenon in the development of Eimeria maxima in terms of decreased nutritional requirements of mature macrogametes, as compared to developing ones; this may also be related to the development of $G$. aculeati.

The taxonomic position of Goussia aculeati has not been fully corroborated by ultrastructural examination of sporocyst walls. However, since light microscope examinations failed to reveal any formations similar to the Stieda body (Jastrzębski 1984), it has been accepted, following Dykova \& Lom's (1981) suggestion, that a species in which the Stieda body is absent most probably belongs to the genus Goussia Labbé.

Acknowledgements. I thank Dr Z. Komorowski, research worker in the Pathology Department of Veterinary Faculty in Warsaw (Poland), for his assistance and advice in the electron microscopic work.

\section{LITERATURE CITED}

Daudi, F., Marques, A., Bouix, G. (1986). Ultrastructure d'Epieimeria isabellae Lom and Dykova, 1982 coccidie épicellulaire parasite intestinal du poisson téleostéen Conger conger Linne, 1758. 24' Colloque G. P. L. F., La Rochelle 16-17 mai 1985. J. Protozool. (Abstr.) 14: 35A

Desser, S. S., Li, L. (1984). Ultrastructural observations on the sexual stages and oocyst formation in Eimeria laureleus (Protozoa, Coccidia) of perch, Perca flavescens from Lake Sasajewun, Ontario. Z. ParasitenKde 70: 153-164

Dykova, I., Lom, J. (1981). Fish coccidia: critical notes on life cycles, classification and pathogenicity. J. Fish Dis. 4 $487-505$

Hawkins, W. E., Solangi, M. A., Overstreet, R. M. (1983a). Ultrastructure of the macrogamont of Eimeria funduli, a coccidium parasitizing killifishes. J. Fish Dis. 6: 33-43
Hawkins, W. E., Solangi, M. A., Overstreet, R. M. (1983b). Ultrastructure of the microgamont and microgamete of Eimeria funduli, a coccidium parasitizing killifishes. J. Fish Dis. 6: $45-57$

Jastrzębski, M. (1984). Coccidiofauna of cultured and feral fishes in fish farms. Wiad. Parazytol. 30 (2): 141-163

Jastrzębski, M., Pastuszko, J., Kurska, E., Badowska, M. (1988). Coccudia of stickleback, Gasterosteus aculeatus (L.). Wiad. Parazytol. 34 (1): 55-63

Jastrzębski, M., Komorowski, Z. (in press). Light and electron microscopic studies on Goussia zarnowskii (Jastrzębski. 1982) - an intestinal coccidium parasitizing the threespined stickleback, Gasterosteus aculeatus (L.). J. Fish Dis. (in press)

Landsberg, J. H., Paperna, I. (1985). Ultrastructure of oogony and sporogony in Goussia cichlidarum Landsberg and Paperna, 1985 a coccidian parasite in the swimbladder of cichlid fish (1). Protistologica 21: 349-359

Landsberg, J. H., Paperna, I. (1986). Ultrastructural study on the coccidian Cryptosporidium sp. from stomachs of juvenile cichlid fish. Dis. aquat. Org. 2: 13-20

Molnar, K. Fernando, C. H. (1974). Some new Eimeria (Protozoa, Coccidia) from freshwater fishes in Ontario, Canada. Can. J. Zool. 52: 413-419

Molnar, K., Baska, F. (1986). Light and electron microscopic studies on Epieimeria anguillae (Léger and Hollande, 1922) a coccidium parasitizing the European eel, Anguilla anguilla L. J. Fish Dis. 9: 99-110

Morrison, C. M., Hawkins, W. E. (1984). Coccidians in the liver and testis of the herring Clupea harengus L. Can. J. Zool 62(3): $480-493$

Paperna, I., Landsberg, J. H., Feinstein, N. (1986). Ultrastructure of the macrogamont of Goussia cichlidarum Landsberg and Paperna, 1985 a coccidian parasite in the swimbladder of cichlid fish. Annls Parasit. hum. comp. 61 $511-520$

Paterson, W. B., Desser, S. S. (1981a). An ultrastructural study of Eimeria irroquoina Molnar and Fernando, 1974 in experimentally infected fathead minnows (Pimephales promelas Cyprinidae) 3. Merogony. J. Protozool. 28: 302-308

Paterson, W B., Desser, S. S. (1981b). Ultrastructure of macrogametogenesis, macrogametes and young oocysts of Eimeria irroquoina in experimentally infected fathead minnows (Pimephales promelas, Cyprinidae) J. Parasit. $67(4): 496-504$

Paterson, W. B., Desser, S. S. (1981C). An ultrastructural study of microgametogenesis and microgamete Eimeria irroquoina Molnar and Fernando, 1974 in experimentally infected fathead minnows (Pimephales promelas Cyprinidae) J. Parasit. 67: 314-324

Paterson, W. B., Desser, S. S. (1984). Ultrastructural observations on fertilization and sporulation in Goussia irroquoina (Molnar and Fernando, 1974) in experimentally infected fathead minnows (Pimephales promelas, Cyprinidae). J. Parasit. 70: 5, 703-711

Pitillo, R. M., Ball, S. J. (1979). The fine structure of the developing macrogamete of Eimeria maxima. Parasitology 79: $259-265$ 